\title{
Prevalence of Women with Dense Breasts in Korea: Results from a Nationwide Cross-sectional Study
}

Hye-Mi Jo, $M P H^{1}$
Eun Hye Lee, MD, $\mathrm{PhD}^{2}$
Kyungran Ko, MD, $\mathrm{Ph}^{3}$
Bong Joo Kang, MD, $P h D^{4}$
Joo Hee Cha, MD, $\mathrm{PhD}^{5}$
Ann Yi, MD, $\mathrm{PhD}$
Hae Kyoung Jung, $\mathrm{MD}^{7}$
Jae Kwan Jun, MD, PhD
On behalf of the Alliance for Breast
Cancer Screening in Korea (ABCS-K)

${ }^{1}$ National Cancer Control Institute, National Cancer Center, Goyang, ${ }^{2}$ Department of Radiology, Soonchunhyang University Bucheon Hospital, Soonchunhyang University College of Medicine, Bucheon, ${ }^{3}$ Center for Breast Cancer, National Cancer Center Hospital, National Cancer Center, Goyang, ${ }^{4}$ Department of Radiology, College of Medicine, The Catholic University of Korea, Seoul, ${ }^{5}$ Department of Radiology, Research Institute of Radiology, Asan Medical Center, University of Ulsan College of Medicine, Seoul, ${ }^{6}$ Department of Radiology, Gangnam Healthcare Center, Seoul National University Hospital, Seoul, ${ }^{7}$ Department of Radiology, CHA Bundang Medical Center,

CHA University, Seongnam, Korea

\section{Purpose}

Women with dense breast are known to be at high risk for breast cancer, but their prevalence and number of Korean women are unknown. The current study was to investigate the distribution of mammographic breast density by age of women undergoing screening mammography, and to estimate the prevalence of Korean women with dense breasts, quantitatively.

\section{Materials and Methods}

For obtaining a nationwide representative sample, 6,481 mammograms were collected from 86 screening units participated in the National Cancer Screening Program for breast cancer. Based on the American College of Radiology Breast Imaging Reporting and Data System classification, breast density was evaluated by six breast radiologists, qualitatively. We applied these breast density distributions to age-specific counts of the Korean women population derived to mid-year 2017 to estimate the number of Korean women with dense breasts.

\section{Results}

Overall, $54.4 \%$ (95\% confidence interval [Cl], 52.9\% to 55.8\%) of women 40 to 69 years of age had heterogeneously or extremely dense breasts, and this proportion was inversely associated with age. Based on the age distribution of Korean women, we estimated that $6,083,000$ women $(95 \% \mathrm{Cl}, 5,919,600$ to $6,245,600)$ age $40-69$ years in Korean have dense breasts. Women aged $40-49$ years $(n=3,450,000)$ accounted for $56.7 \%$ of this group.

\section{Conclusion}

More than half of Korean women aged 40 and over have dense breasts. To prevent breast cancer effectively and efficiently, it is necessary to develop a new personalized prevention strategy considering her status of breast density.

Key words

Breast density, Prevalence, Mammography, Korea
Correspondence: Jae Kwan Jun, MD, PhD National Cancer Control Institute, National Cancer Center, 323 Ilsan-ro, Ilsandong-gu, Goyang 10408, Korea Tel: 82-31-920-2184

Fax: 82-31-920-2929

E-mail: jkjun@ncc.re.kr

Received May 23, 2018

Accepted January 27, 2019

Published Online January 29, 2019 


\section{Introduction}

The mammographic breast density (MBD) is the extent of the radio-opacified fibroglandular tissue of breast in the mammogram. The MBD, measured qualitatively or quantitatively, is well-known as a risk factor for breast cancer in Western women $[1,2]$. Recent studies have reported that it might be a risk factor in Asian women [3,4].

It is used as a surrogate marker of breast cancer prevention [5] and makes a model for predicting a risk of breast cancer in individuals more accurate [6]. Moreover, in women with dense breast, the MBD makes it difficult to detect breast cancer, which decreases the accuracy of mammography screening $[7,8]$.

Age is most likely associated with the MBD, which is decreased by age. In addition, anthropometric, parity, and hormonal factors known as the risk factor of breast cancer are also associated with the MBD [9]. Although many epidemiological studies including immigration studies reported that there are ethnic and geographic differences in the MBD [10-14], most of them have a problem of small sample size and representativeness of populations. In Asian women, the proportions of women with dense breast may be higher than those of western women.

Many Korean women are known to have small breast volume and a higher proportion of dense breasts $[15,16]$. However, to date, there is no study on the distribution of breast density using a large-scale and representative sample of asymptomatic Korean women. The objective of this study, therefore, is to examine the distribution of MBD by age in women undergoing screening mammography and estimate the prevalence of Korean women with dense breasts. Using the recent studies conducted with a representative sample $[17,18]$, we sought to examine differences between Korean women and other countries.

\section{Materials and Methods}

\section{Study population}

The Korean Mammographic Density (KoMAD) study was designed to estimate the prevalence of dense breast representatively and to determine the association between breast density and breast cancer risk in Korean women. It was conducted from January 2012 to December 2014. The design and study enrolment have been fully described in detail previously $[4,19]$. Briefly, the eligible population of this study consisted of women aged 40 years and over who participated in
Table 1. General characteristics of the study population

\begin{tabular}{|c|c|}
\hline & No. $(\%)(n=6,481)$ \\
\hline Age, mean $\pm S D(y r)$ & $55.01 \pm 11.0$ \\
\hline \multicolumn{2}{|l|}{ Age at menarche (yr) } \\
\hline$\leq 13$ & $546(8.4)$ \\
\hline $14-16$ & $3,605(55.6)$ \\
\hline$\geq 17$ & $2,279(35.2)$ \\
\hline Missing & $51(0.8)$ \\
\hline \multicolumn{2}{|l|}{ No. of live births } \\
\hline 0 & $286(4.4)$ \\
\hline 1 & $699(10.8)$ \\
\hline$\geq 2$ & $5,471(84.4)$ \\
\hline Missing & $25(0.4)$ \\
\hline \multicolumn{2}{|l|}{ Breast feeding (mo) } \\
\hline Never & $774(11.9)$ \\
\hline$<12$ & $2,128(32.8)$ \\
\hline$\geq 12$ & $3,578(55.2)$ \\
\hline Missing & $1(0.0)$ \\
\hline \multicolumn{2}{|l|}{ Age at menopause (yr) } \\
\hline Premenopausal & $83(1.3)$ \\
\hline$<45$ & $259(4.0)$ \\
\hline $45-54$ & $3,490(53.9)$ \\
\hline$\geq 55$ & $411(6.3)$ \\
\hline Missing & $2,238(34.5)$ \\
\hline \multicolumn{2}{|l|}{ Hormone replacement therapy } \\
\hline Never & $5,433(83.8)$ \\
\hline Ever & $720(11.1)$ \\
\hline Missing & $328(5.1)$ \\
\hline \multicolumn{2}{|l|}{ Oral contraceptive use (mo) } \\
\hline Never & $5,224(80.6)$ \\
\hline$<12$ & $622(9.6)$ \\
\hline$\geq 12$ & $320(4.9)$ \\
\hline Missing & $315(4.9)$ \\
\hline \multicolumn{2}{|l|}{ Past history of benign disease } \\
\hline Yes & $528(8.1)$ \\
\hline No & $5,459(84.2)$ \\
\hline I do not know & $459(7.1)$ \\
\hline Missing & $35(0.5)$ \\
\hline \multicolumn{2}{|l|}{ Breast density } \\
\hline Almost entirely fat & $1,212(18.7)$ \\
\hline Scattered fibroglandular densities & $1,862(28.7)$ \\
\hline Heterogeneously dense & $2,212(34.1)$ \\
\hline Extremely dense & $1,195(18.4)$ \\
\hline
\end{tabular}

$\mathrm{SD}$, standard deviation.

the National Cancer Screening Program (NCSP) in 2009. To prevent over-representation of specific regions, the participants were randomly selected after stratification by 16 administrative districts and the proportion of women aged $\geq 40$ years in each region. To ensure accessibility of mammo- 


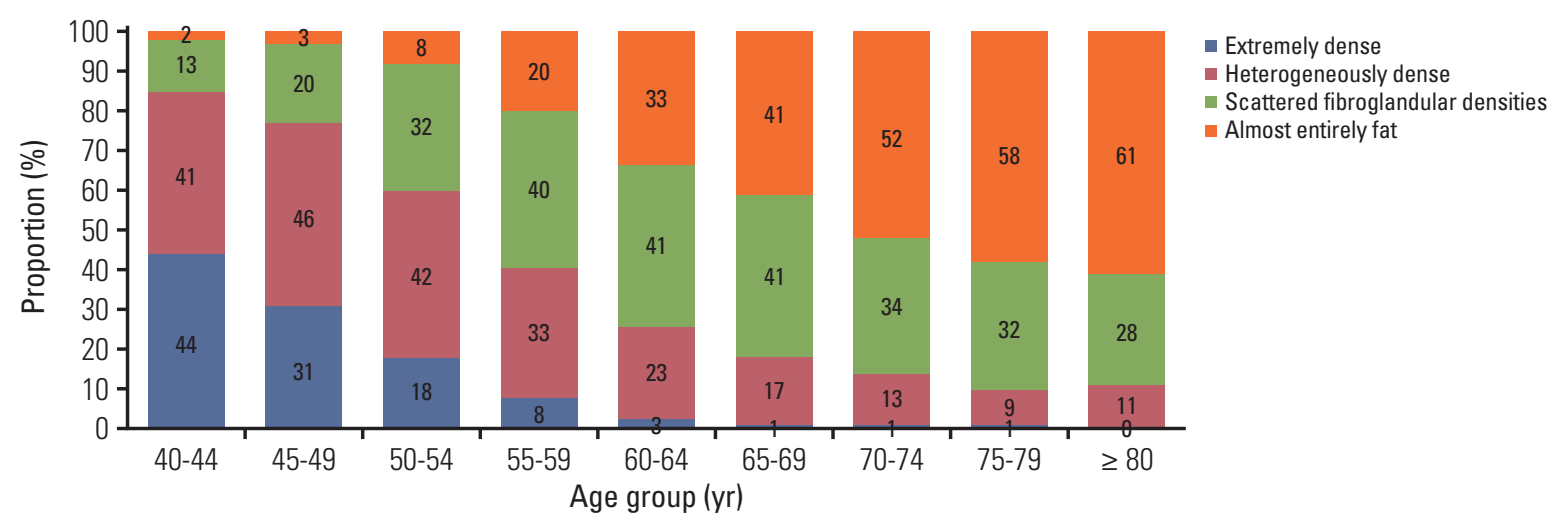

Fig. 1. Distribution of breast density categories of American College of Radiology (ACS) Breast Imaging Reporting and Data System (BI-RADS) by age in Korean women.

grams, screening units were restricted to a total amount of mammograms annually. Imaging data were collected from a total of 86 screening units representing their respective district regions. The mammographic images were obtained from the screening units in the form of original analog film copy or Digital Imaging and Communication in Medicine (DICOM) file. Among the selected women, 962 women $(12.9 \%)$ whose were not stored craniocaudal and mediolateral oblique images of both breasts, or whose was not re-readable film status, were excluded. Finally, mammograms for 6,481 women were included in this study.

\section{Mammography reading}

The MBD was measured qualitatively according to the American College of Radiology (ACR) Breast Imaging Reporting and Data System (BI-RADS) classification (4th edition) of breast density [20]. Six radiologists who are active members of the Korean Society of Breast Imaging and breast specialists in general hospitals participated in this study. To reduce variability in evaluating $M B D$, six breast radiologists were trained in the ACR BI-RADS classification of breast density. Prior to read mammography images in this study, the inter-radiologist agreement of ACR BI-RADS classification was evaluated. Based on pilot test, radiologists showed substantial agreement for measurement of MBD: the weighted kappa value for inter-radiologist agreement was 0.83 (95\% confidence interval [CI], 0.80 to 0.86) [21]. They were paired into three groups to read MBD. If two radiologists' read were not consistent, they discussed to reach an agreement. Each BI-RADS density grade was classified as follows [20]: almost entirely fat (0\%-25\% glandular); scattered fibroglandular densities (26\%-50\% glandular); heterogeneously dense (51\%75\% glandular); and extremely dense (76\%-100\% glandular). Density classifications were grouped almost entirely fat and scattered fibroglandular densities as "fatty breasts" and heterogeneously or extremely dense as "dense breasts."

\section{Statistical analysis}

We used the distribution of MBD by age groups for estimating prevalence of breast density and its 95\% CI in Korean women. For estimating counts of women with a dense breast by age group, we obtained data from the 2017 Korean Census. By multiplying the weighted frequency by the corresponding mid-year population, we calculated a weighted frequency for each age group. All other statistical analyses were conducted using SAS Statistical Software, ver. 9.2 (SAS Institute Inc., Cary, NC).

\section{Ethical statement}

With permission from the Ministry of Health and Welfare, informed consent for this study was not required, which was approved by the Institutional Review Board (IRB) of the National Cancer Center, IRB number NCC2014-0065.

\section{Results}

Table 1 shows the characteristics of the study participants and their breast densities. About $11.1 \%$ of the participants reported having used hormones. This study included 1,212 women (18.7\%) in the "almost entirely fat," 1,862 women $(28.7 \%)$ in the "scattered fibroglandular densities," 2,212 women (34.1\%) in the "heterogeneously dense," and 1,195 women $(18.4 \%)$ in the "extremely dense" groups.

Fig. 1 shows the distribution of breast density measured 


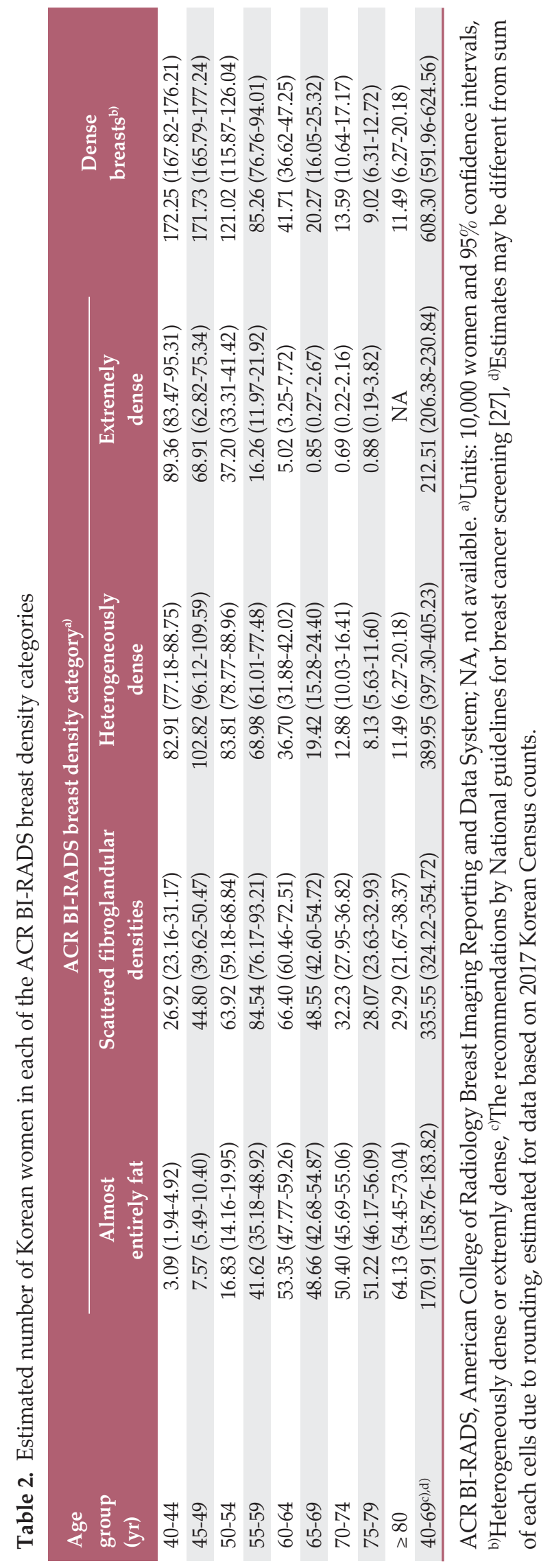




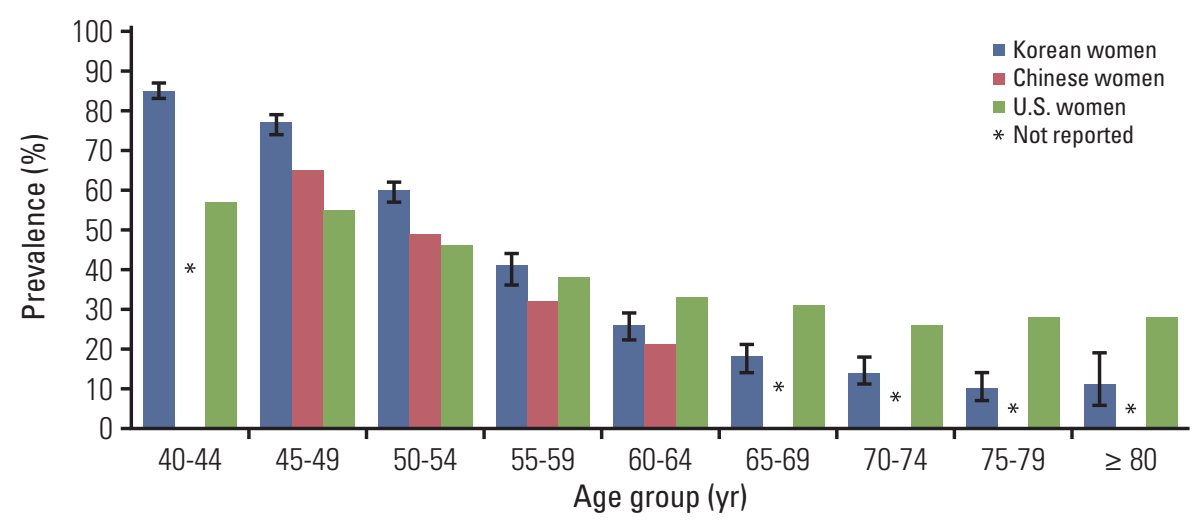

Fig. 2. Comparison of prevalences of dense breasts between Korean women, Chinese women [18], and U.S. women [17] by age.

by four BI-RADS categories for women aged 40 years and older in this study. The highest proportions by each age group were as follows: extremely dense $(44.2 \%)$ for aged 40 44 years, heterogeneously dense (43.7\%) for aged 45-54 years, scattered fibroglandular tissue (40.5\%) for aged 55-64 years, and almost entirely fat $(53.2 \%)$ for aged 65 years and older. The proportions of dense breasts declined with increasing age. Similar trends were observed when stratified by health insurance status (S1 Fig.). It sharply decreased in Korean women aged 55-59 years. Women with dense breasts in their 40s showed more than $70 \%$, but they fell to less than $10 \%$ from the age of 65 . Overall, $45.6 \%$ (95\% CI, $44.2 \%$ to $47.0 \%$ ) in the Korean women aged 40 years and older, which was estimated at 6,420,226 women ( $95 \%$ CI, 6,223,110 to 6,617,340) had heterogeneously or extremely dense breasts (Table 2 ). For women aged 40 to 69 years, $54.4 \%(95 \% \mathrm{CI}, 52.9$ to 55.8$)$ and 6,083,000 women (95\% CI, 5,919,600 to $6,245,600)$ were estimated, respectively.

Our results were compared with prior studies conducted in United States and China is presented in Fig. 2. Similar to our results, the prevalence of MBD in United States and Chinese women decreased with increasing age. Until the age of 60 , the prevalence of MBD of Korean women was higher than that of U.S. women. At age 60, U.S. women with dense breasts began to outstrip Korean women with dense breasts. Within comparable age groups, the trend in Chinese women was similar to that in Korean women.

\section{Discussion}

We quantitatively estimated Korean women with dense breasts, which might be one of major risk factors for breast cancer. Among all Korean women aged 40 years and over, who are the target population of the NCSP for breast cancer, we estimated that the proportion of women with heterogeneously or extremely dense breasts is approximately $45.6 \%$, corresponding to approximately 6,420,226 Korean women. Restricted to aged 40-69 years, which most guidelines for breast cancer screening recommend, the proportion was increased to $54.4 \%$ (6,083,000 women).

In comparison to Sprague et al.'s study [17], we found differences in the distribution of mammographic density according age group between women in Korean and United States. There result of the overall tendency with aging was similar to our results. However, the proportion of women with dense breasts in Korean was higher than $80 \%$ until their late 40 s, and then there was a sharp decrease in the proportion upper 50 years. By comparing the characteristic change in breast, it is that Korean women in aged between 40 and 54 years were a much greater proportion of dense breasts than U.S. women, and that the transfer from dense breasts to fatty breasts tends to change more rapidly than U.S. women. Our results in the proportion of breast density according age group are similar to prior studies in China and Japan. The proportion of women with dense breasts in China and Japan was higher in under 50 years of age, and then breast density tends to decrease with increasing age. But, Ishihara et al. [22] has limitation in making comparisons with our results because a quoted age standards are different and absolute density was not evaluation in their study.

Since 2002, the NCSP for breast cancer has been conducted for all Korean women aged 40 years old and over, biennially. To date, the participation rate is about $52 \%$ and more than 3.3 million women are receiving screening mammography each year [23]. Higher recall rates of NCSP, especially over $20 \%$ in aged 40s than those of other screening programs in Western countries was reported [24]. Women with extremely 
dense breast were 7 times more likely to recall than women with almost entirely fatty breast [25]. It might be due to risk of interval cancer in women with dense breast and concerns about subsequent medical litigation.

An important effect of high breast density is the risk of a false-negative mammography finding due to the masking effect of dense tissue $[7,8]$. An interval cancer diagnosed in woman with dense breasts has led to legislation in the United States that mandates disclosure of breast density information to women undergoing mammography screening. Since breast density notification law was first enacted in Connecticut in 2009, it has been put into effect in 35 states and requires direct screen notification on mammographic results indicating the presence of dense breasts [26]. It has been estimated that more than 25 million women with dense breasts in the United States could be affected by the breast density notification laws [17]. On the other hand, in Korea, the NCSP started to record breast density information in 2009, but it does not notified to participants.

Some limitations of this study regarding interpreting result exist. First, we evaluated MBD according BI-RADS density classification qualitatively. Although the BI-RADS classification is widely used, its assessments depend on the ability and experience of radiologists and may show reader variability. In order to overcome the limitations of qualitative methods, quantitative breast density analysis is needed with more objective and higher reproducibility, but supplying digital radiographic system for mammography is essential. Second, we could not consider the other factors that can influence breast density in this study, such as the body mass index, reproductive and hormonal factors, or socioeconomic status. However, our study minimized the effects of these external factors by applying a representative sampling strategy. Third, there were discrepancies between the time when the survey was conducted and the yearly population data used for estimation of the counts of women with dense breasts. Although there is no evidence that the prevalence of MBD by age changes with the calendar year, further studies are required to determine the changes in breast density over time through repeated measurements.

Despite these limitations, our study is meaningful because this is nationwide survey for estimating the distribution of MBD among Korean women and counting women with dense breasts quantitatively. It could be utilized as principal evidence for developing the preventing strategy for breast cancer such as screening.

Our results indicate the underlying prevalence of dense breasts among the Korean women aged 40 years and older. More than half of the Korean women have dense breasts. In spite of limited evidences [27], Korean women with dense breasts are recommended supplemental screening such as breast ultrasonography. More than 19,000 breast cancers are newly diagnosed each year and it is expected that the number will continue to increase in near future $[28,29]$. To prevent breast cancer effectively and efficiently, it is necessary to develop a new personalized prevention strategy considering her status of breast density.

\section{Electronic Supplementary Material}

Supplementary materials are available at Cancer Research and Treatment website (https:// www.e-crt.org).

\section{Conflicts of Interest}

Conflict of interest relevant to this article was not reported.

\section{Acknowledgments}

This research was supported by a grant of the Korea Health Technology R\&D project through the Korea Health Industry Development Institute (KHIDI), funded by the Ministry of Health \& Welfare, Republic of Korea (grant number: HC15C1257).

\section{References}

1. Boyd NF, Martin LJ, Yaffe MJ, Minkin S. Mammographic density and breast cancer risk: current understanding and future prospects. Breast Cancer Res. 2011;13:223.

2. Astley SM, Harkness EF, Sergeant JC, Warwick J, Stavrinos P, Warren R, et al. A comparison of five methods of measuring mammographic density: a case-control study. Breast Cancer Res. 2018;20:10.

3. Bae JM, Kim EH. Breast density and risk of breast cancer in Asian women: a meta-analysis of observational studies. J Prev
Med Public Health. 2016;49:367-75.

4. Park B, Cho HM, Lee EH, Song S, Suh M, Choi KS, et al. Does breast density measured through population-based screening independently increase breast cancer risk in Asian females? Clin Epidemiol. 2018;10:61-70.

5. Nyante SJ, Sherman ME, Pfeiffer RM, Berrington de Gonzalez A, Brinton LA, Aiello Bowles EJ, et al. Prognostic significance of mammographic density change after initiation of tamoxifen for ER-positive breast cancer. J Natl Cancer Inst. 2015;107: 
dju425.

6. Tice JA, Cummings SR, Smith-Bindman R, Ichikawa L, Barlow WE, Kerlikowske K. Using clinical factors and mammographic breast density to estimate breast cancer risk: development and validation of a new predictive model. Ann Intern Med. 2008; 148:337-47.

7. Trentham-Dietz A, Kerlikowske K, Stout NK, Miglioretti DL, Schechter CB, Ergun MA, et al. Tailoring breast cancer screening intervals by breast density and risk for women aged 50 years or older: collaborative modeling of screening outcomes. Ann Intern Med. 2016;165:700-12.

8. Holm J, Humphreys K, Li J, Ploner A, Cheddad A, Eriksson $\mathrm{M}$, et al. Risk factors and tumor characteristics of interval cancers by mammographic density. J Clin Oncol. 2015;33:1030-7.

9. Boyd NF, Rommens JM, Vogt K, Lee V, Hopper JL, Yaffe MJ, et al. Mammographic breast density as an intermediate phenotype for breast cancer. Lancet Oncol. 2005;6:798-808.

10. Maskarinec G, Nagata C, Shimizu H, Kashiki Y. Comparison of mammographic densities and their determinants in women from Japan and Hawaii. Int J Cancer. 2002;102:29-33.

11. Maskarinec G, Pagano I, Chen Z, Nagata C, Gram IT. Ethnic and geographic differences in mammographic density and their association with breast cancer incidence. Breast Cancer Res Treat. 2007;104:47-56.

12. Mariapun S, Li J, Yip CH, Taib NA, Teo SH. Ethnic differences in mammographic densities: an Asian cross-sectional study. PLoS One. 2015;10:e0117568.

13. McCormack VA, Perry N, Vinnicombe SJ, Silva Idos S. Ethnic variations in mammographic density: a British multiethnic longitudinal study. Am J Epidemiol. 2008;168:412-21.

14. Habel LA, Capra AM, Oestreicher N, Greendale GA, Cauley JA, Bromberger J, et al. Mammographic density in a multiethnic cohort. Menopause. 2007;14:891-9.

15. Kim SH, Kim MH, Oh KK. Analysis and comparison of breast density according to age on mammogram between Korean and western women. J Korean Radiol Soc. 2000;42:1009-14.

16. Youn I, Choi S, Kook SH, Choi YJ. Mammographic breast density evaluation in Korean women using fully automated volumetric assessment. J Korean Med Sci. 2016;31:457-62.

17. Sprague BL, Gangnon RE, Burt V, Trentham-Dietz A, Hampton JM, Wellman RD, et al. Prevalence of mammographically dense breasts in the United States. J Natl Cancer Inst. 2014; 106:dju255.
18. Dai H, Yan Y, Wang P, Liu P, Cao Y, Xiong L, et al. Distribution of mammographic density and its influential factors among Chinese women. Int J Epidemiol. 2014;43:1240-51.

19. Jun JK, Kim MJ, Choi KS, Suh M, Jung KW. Development of a sampling strategy and sample size calculation to estimate the distribution of mammographic breast density in Korean women. Asian Pac J Cancer Prev. 2012;13:4661-4.

20. American College of Radiology. Breast Imaging Reporting and Data System. 4th ed. Reston, VA: American College of Radiology; 2003.

21. Jo HM, Song S, Lee EH, Ko K, Kang BJ, Cha JH, et al. Interpretive volume and inter-radiologist agreement on assessing breast density. J Korean Soc Breast Screening. 2018;15:15-22.

22. Ishihara S, Taira N, Kawasaki K, Ishibe Y, Mizoo T, Nishiyama $\mathrm{K}$, et al. Association between mammographic breast density and lifestyle in Japanese women. Acta Med Okayama. 2013;67:145-51.

23. Suh M, Song S, Cho HN, Park B, Jun JK, Choi E, et al. Trends in participation rates for the national cancer screening program in Korea, 2002-2012. Cancer Res Treat. 2017;49:798-806.

24. Lee EH, Kim KW, Kim YJ, Shin DR, Park YM, Lim HS, et al. Performance of screening mammography: a report of the Alliance for Breast Cancer Screening in Korea. Korean J Radiol. 2016;17:489-96.

25. Kim YJ, Lee EH, Jun JK, Shin DR, Park YM, Kim HW, et al. Analysis of participant factors that affect the diagnostic performance of screening mammography: a report of the Alliance for Breast Cancer Screening in Korea. Korean J Radiol. 2017;18:624-31.

26. Are You Dense Advocacy Inc. [Internet]. Woodbury, CT: Are You Dense Advocacy Inc.; 2018 [cited 2018 Apr 13]. Available from: http:// www.areyoudenseadvocacy.org.

27. Lee EH, Park B, Kim NS, Seo HJ, Ko KL, Min JW, et al. The Korean guideline for breast cancer screening. J Korean Med Assoc. 2015;58:408-19.

28. Jung KW, Won YJ, Kong HJ, Lee ES; Community of Population-Based Regional Cancer Registries. Cancer statistics in Korea: incidence, mortality, survival, and prevalence in 2015. Cancer Res Treat. 2018;50:303-16.

29. Jung KW, Won YJ, Kong HJ, Lee ES. Prediction of cancer incidence and mortality in Korea, 2018. Cancer Res Treat. 2018; 50:317-23. 